José Augusto Pina ${ }^{1}$

Eduardo Navarro Stotz ${ }^{2}$

\section{Participação nos lucros ou resultados e banco de horas: intensidade do trabalho e desgaste operário}

\author{
Profit sharing and flexible working hours: intense workload \\ and worker's wearing down
}

${ }^{1}$ Centro de Estudos da Saúde do Trabalhador e Ecologia Humana (CESTEH), Escola Nacional de Saúde Pública Sergio Arouca (ENSP), Fundação Oswaldo Cruz (Fiocruz), Rio de Janeiro, Brasil.

2 Departamento de Endemias Samuel Pessoa (DENSP), Escola Nacional de Saúde Pública Sergio Arouca (ENSP), Fundação Oswaldo Cruz (Fiocruz), Rio de Janeiro, Brasil.

Contato:

José Augusto Pina

Avenida Leopoldo Bulhões, 1480

Manguinhos, Rio de Janeiro - RJ

CEP 21041-210

E-mail:

augusto@ensp.fiocruz.br
Recebido: 17/06/2010

Revisado 16/11/2010

Aprovado: 19/11/2010

\section{Resumo}

Introdução: As transformações operadas no processo de trabalho na indústria automobilística no Brasil desde os anos 1990 apontam para o fortalecimento da gestão da força de trabalho como um dos determinantes do processo saúde-doença dos trabalhadores. Objetivos: Discutem-se dois elementos da gestão: a participação nos lucros ou resultados (PLR) e o banco de horas (BH) e assinala-se a relação de ambos com a intensidade do trabalho e o desgaste operário. Métodos: Apóia-se em revisão bibliográfica e em análise dos acordos coletivos dos metalúrgicos do ABC-SP, entre 2001 e 2008. Resultados: A análise realizada mostrou que a reorganização do tempo de trabalho, o prolongamento da jornada e a manutenção do elevado grau de intensidade do trabalho ocasionados pelo $\mathrm{BH}$ e as metas vinculadas à PLR exercem pressão sobre o trabalhador para o aumento quantitativo e qualitativo do trabalho, evidenciando que esses instrumentos gerenciais propiciam a intensificação do trabalho e o desgaste operário. Também afetam drasticamente o tempo de não trabalho fora da jornada, inclusive prejudicando a reposição e o desenvolvimento da capacidade biopsíquica do trabalhador. Conclusão: A PLR e o $\mathrm{BH}$ podem ser caracterizados como uma forma de administração por estresse que eleva e potencializa as cargas de trabalho e o desgaste operário.

Palavras-chaves: saúde do trabalhador; participação nos lucros ou resultados; banco de horas; desgaste operário; intensidade e prolongamento do trabalho.

\begin{abstract}
Introduction: Changes introduced in Brazilian automotive industry working process since the 1990s have increased the weight of workforce management as determinant of workers' health. Background: This article discusses two elements of management: profit or result sharing (PRS) and flexible working hours (FWH), drawing attention to the relationship between these two aspects and work intensity as well as workers' wearing down. Method: Literature review and analysis of collective agreements negotiated by the metalworkers' union in ABC-SP (Santo Andre, São Bernardo and São Caetano - three industrial centers in São Paulo metropolitan area), between 2001 and 2008. Results: The analysis showed that reorganization and lengthening of working time as well as high work intensity, both resulting from PRS goal achievement process and FWH, push workers towards qualitative and quantitative increase of their work, evidencing that these managerial tools cause work intensification and workers' wearing down. Time off work is also affected, hindering workers' recovery and biopsychic ability development as well. Conclusion: PRS and FWH can be characterized as models of management by stress, which increase workload and workers' wearing down.
\end{abstract}

Keywords: workers' health; profits sharing; flexible working hours; workers' wearing down; intense workload and longer working time. 


\section{Introdução}

As transformações operadas no processo de trabalho imediato apontam para o fortalecimento da gestão da força de trabalho como um dos determinantes do processo saúde-doença dos trabalhadores. Este artigo discute dois elementos da gestão: a participação nos lucros ou resultados (PLR) e o regime de compensação das horas trabalhadas conhecido como banco de horas. Tem por objetivo assinalar a relação entre ambos os mecanismos com a intensidade do trabalho e o desgaste operário, considerando as implicações para a saúde dos trabalhadores.

Em diversos países, modalidades de remuneração variável e reorganização do tempo de trabalho ganharam destaque na regulação das relações de trabalho após a crise econômica de 1973-75. O contexto econômico, político e social de então era instável; por um lado, saturação dos principais mercados, recessão ou baixo crescimento econômico e acirramento da concorrência internacional (MENDONÇA, 1990), de outro, estabelecimento de legislação sobre direitos dos trabalhadores nos locais de trabalho conquistada em decorrência dos protestos contra a aceleração do ritmo de trabalho, de absenteísmo, greves e mobilizações operárias, com destaque para o "maio de 1968” na França e o "outono quente" em 1969 na Itália, com sucessivos questionamentos à hierarquia e à gestão capitalista da produção (ROTHSCHILD, 1974; NAVARRO, 1993).

Para enfrentar esse quadro, as empresas desencadearam um processo de reestruturação produtiva intra e interfimas e de restituição do poder gerencial com a incorporação da flexibilidade na utilização da força de trabalho. Entre as modalidades de flexibilidade mais difundidas, nas últimas décadas, nos principais países capitalistas, estão a remuneração variável por meio de pagamentos de prêmios por ganhos ou resultados das empresas e as alterações na gestão do tempo de trabalho com programas de modulação da jornada de trabalho (DEDECCA, 1999).

Na União Europeia (UE), a ampla utilização dos regimes PEPPER (Participation of Employees in Profits and Enterprise Results), que reúnem as diversas modalidades de participação financeira dos trabalhadores na empresa, é considerada "uma fonte potencial para aumentar a competitividade da UE” (UVALIĆ, 2009, p. 181).

Os relatórios PEPPER I a IV, entre 1991 e 2009, e estudos empíricos apontam efeitos positivos na produtividade do trabalho com a adoção dos regimes PEPPER (UVALIĆ, 2009). Tais programas favoreceriam o aumento da identificação, da motivação e do compromisso do trabalhador com os resultados da empresa. Mas existem grandes diferenças no interior da UE: uma maior amplitude e regularidade dos PEPPER nos países da Europa Ocidental, em especial nos Estados que dispõem de legislação específica (França, Reino Unido e Irlanda), enquanto, nos países do Leste, apesar de recente expansão, ela acontece quase exclusivamente por meio da aquisição, pelos trabalhadores, de ações de empresas privatizadas (UVALIĆ, 2009).
Quanto à jornada de trabalho, historicamente, a luta orientou-se no sentido de sua redução para ampliação do tempo livre. Mas, nas últimas décadas, essa tendência tem sido revertida: elevou-se nos EUA; no Japão, apesar da redução, o tempo de trabalho e as horas extras se mantém em níveis bastante elevados; e na UE o ritmo de redução da jornada semanal de trabalho tem sido mais lento. A gestão da jornada tornou-se uma "ferramenta competitiva na redução de custos de produção” (DEMETRIADES; PEDERSINI, 2008, p. 48) das empresas. A par das especificidades e das diferentes formas de regulação da jornada no Japão, nos EUA e nos países da UE, a flexibilização dos horários e a erosão da fronteiras entre tempo de trabalho e tempo livre têm se afirmado como tendências comuns no âmbito mundial (DEMETRIADES; PEDERSINI, 2008).

Examinamos, a seguir, de modo sucinto, o contexto histórico brasileiro no qual se situam a implantação e a difusão da PLR e do banco de horas como modalidades de gestão da força de trabalho.

Para entender o significado político da PLR e do banco de horas, é necessário situar estes instrumentos de regulação das relações entre capital e trabalho no âmbito das empresas como parte da estratégia governamental de estabilização econômica. O desafio de controlar a inflação implicava encontrar uma forma estável de exploração do trabalho (mais-valia), base da acumulação de capital e, portanto, do crescimento econômico, capaz de viabilizar a integração - sem alterar a condição de dependência do país - na nova dinâmica da economia capitalista em escala mundial (MEYER, 1996).

Esse processo não se deu num único momento e tampouco resultou de uma intervenção racional do Estado, acima do conflito de interesses entre capital e trabalho.

O cenário no qual a PLR e o banco de horas emergem desenhou-se com as câmaras setoriais. O objetivo explícito das câmaras era dar conta da questão de preços e do aumento da produtividade do ponto de vista dos interesses capitalistas dos diferentes setores da indústria (ANDERSON, 1999). Nesse momento, grandes empresas, inclusive as montadoras de autoveículos, desencadearam um processo de reestruturação produtiva e interessava reduzir os conflitos e a resistência interna dos trabalhadores (STOTZ, 1996).

A participação dos trabalhadores na Câmara Setorial da Indústria Automotiva foi incluída no governo Itamar Franco. Para os trabalhadores, havia uma situção de urgência criada com o fechamento da fábrica de motores da Ford em São Bernardo do Campo. A liderança sindical dos metalúrgicos empreendeu então a negociação com as empresas e o governo para favorecer a recuperação da indústria automobilística e, assim, do nível de emprego no ramo. A experiência da Câmara Setorial da Indústria Automotiva ou Acordo das Montadoras é um assunto polêmico uma vez que teria representado o fim da política de resistência e confronto que, nos anos 1980, caracterizara o movimento sindical (RODRIGUES, 2002). 
Mas esta iniciativa foi entendida como uma forma corporativista de relações entre capital e trabalho pela maioria do empresariado e inclusive por parte da intelectualidade. Fernando Henrique Cardoso vocalizou esses interesses ao afirmar que o acordo entre sindicatos e montadoras ia em direção contrária à solução para a retomada do crescimento da economia, consubstanciada no Plano Real. Este plano, iniciado em fevereiro de 1994 com a publicação da Medida Provisória nํㅜ 434, implicava uma divisão de ganhos e perdas de renda que favoreceria o capital em detrimento do trabalho.

A contestação dos trabalhadores teve à frente a greve nacional dos petroleiros, ao final derrotada, considerada por Maar (2003) "ato exemplar" do governo e uma vitória política sobre o movimento sindical.

No decorrer da greve dos petroleiros, o governo resolveu regulamentar o inciso XI do artigo $7^{\circ}$ da Constituição Federal, que estabelece a "participação nos lucros, ou resultados, desvinculada da remuneração, e, excepcionalmente, participação na gestão da empresa, conforme definido em lei" (BRASIL, 1988), por meio da Medida Provisória nº 794 de 29 de dezembro de 1994. Nascia o instituto da Participação nos Lucros ou Resultados que, depois de sucessivas reedições com alteraÇões no texto inicial, foi transformada na Lei $\mathrm{n}^{\mathbf{0}} 10.101$ de 19 de dezembro de 2000.

Pode-se dizer que a PLR nasce sobre os destroços do sindicalismo que, sob a liderança da Federação Única dos Petroleiros, deu ênfase à mobilização coletiva no plano nacional e questionou os ganhos do conjunto dos capitalistas obtidos com o Plano Real (LOBO; STOTZ, 2004).

Quanto ao banco de horas, trata-se de uma mudança na gestão do tempo de trabalho, tanto em sua quantidade, quanto na forma de utilização da força de trabalho. Quando a Lei nº 9.601, em 21 de janeiro de 1998, introduziu o dispositivo conhecido como "banco de horas", este já era objeto de acordo coletivo em diversas empresas (COSTA, 2002; DEPARTAMENTO INTERSINDICAL DE ESTATÍSTICA E ESTUDOS SOCIOECONÔMICOS, 2002).

Apesar da ocorrência de acordos coletivos entre sindicatos de trabalhadores e empresas relativos à PLR e ao banco de horas, a regulamentação legal pelo Estado impulsionou a difusão desses instrumentos e ressalta a forma ativa da intervenção estatal na gestão da força de trabalho no interior da empresa.

A PLR introduz na relação salarial uma modalidade de remuneração variável e condicionada a resultados. Em relação à PLR, este estudo destaca: a característica da remuneração condicionada a metas, sua relação com as formas de organização do trabalho e a intensidade do trabalho. O banco de horas, por sua vez, possibilitou reorganizar o tempo de trabalho com alterações nas formas de utilização da força de trabalho. O banco de horas será considerado quanto às formas e aos critérios de compensação das horas, à relação com o prolongamento e a intensidade do trabalho, bem como com outros elementos da organização do trabalho. Observamos a relação mútua entre a PLR e o banco de horas. Ambos podem potencializar as cargas de trabalho e produzir alterações nos padrões de desgaste operário.

Utilizamos a categoria desgaste para designar as transformações negativas decorrentes da interação dinâmica das cargas de trabalho nos processos biopsíquicos de uma determinada coletividade de trabalhadores, "entendido como a perda da capacidade potencial e/ou efetiva corporal e psíquica” (LAURELL; NORIEGA, 1989, p. 110).

\section{Metodologia}

O presente estudo apoia-se numa revisão bibliográfica. A consulta foi realizada nas bases virtuais da SciELO Brasil (Scientific Electronic Library Online), até dezembro de 2009, e do Banco de Teses da Coordenação de Aperfeiçoamento de Pessoal de Nível Superior (Capes), até o ano base 2009. Em ambas as bases, a busca abrangeu o campo "Assunto" para as seguintes palavras-chaves: "participação nos lucros e resultados", "participação nos resultados”, "remuneração variável”, "flexibilização da jornada de trabalho", "banco de horas" e "compensação de horário". Na Capes, utilizou-se a "expressão exata” e na Scielo, o conectivo "AND" para combinar os termos quando não havia descritores para a palavra-chave.

A seleção compreendeu os trabalhos com a discussão da PLR e do banco de horas acima delimitada. Priorizamos os estudos nas montadoras da indústria automobilística por seu pioneirismo na introdução dos dois mecanismos, seu alto poder em disseminar modalidades de gestão da força de trabalho para outros ramos produtivos e pela organização sindical dos trabalhadores.

A busca e a leitura dos resumos e dos trabalhos selecionados foram realizadas entre 19 de setembro de 2008 e 30 de abril de 2010. A leitura dos resumos, particularmente das Teses e Dissertações, revelou a grande concentração de estudos nas áreas de Administração e Direito.

Dos 207 resumos encontrados (198 na Capes e 09 na Scielo), 30 foram selecionados e 177 excluídos: 122 estavam fora da temática e 55 não atendiam os critérios da discussão indicada. A partir da leitura dos estudos selecionados pelos critérios de elegibilidade, incluímos outros 07 trabalhos obtidos por referência cruzada e 09 foram excluídos por evidência de duplicidade: tese ou dissertação que geraram livro e/ou artigo, sendo estes (nessa ordem) escolhidos para extração dos dados e análise. Acrescentamos ainda 08 trabalhos produzidos pelo Departamento Intersindical de Estatística e Estudos Socioeconômicos (Dieese) e/ou entidades sindicais, conforme sintetizado no Quadro 1.

Além da bibliografia, adicionamos o levantamento e a análise dos Acordos Coletivos de Trabalho específicos à temática entre o Sindicato dos Metalúrgicos do ABC-SP e as montadoras de veículos da região, no período de 2001 a 2008. Assim, com base nos objetivos e no referencial teórico, extraiu-se os dados dos acordos coletivos para subsidiar a discussão da intensidade do trabalho e do processo de desgaste operário. 
Quadro 1 Leitura da bibliografia consultada e selecionada

\begin{tabular}{|c|c|}
\hline \multicolumn{1}{|c|}{ Resumos } & Trabalhos na íntegra \\
\hline 207 resumos encontrados & 36 trabalhos selecionados \\
198 teses e dissertações (Capes) & 30 estudos (critérios de elegibilidade) \\
09 artigos (Scielo) & 07 incluídos por referência cruzada \\
177 resumos excluídos: & 09 excluídos por duplicidade \\
122 de outros temas & 10 teses e dissertações \\
55 fora dos critérios da discussão & 09 artigos em periódicos \\
30 resumos selecionados & 04 capítulos de livro \\
& 04 livros \\
& 01 trabalho em Congresso \\
& 08 trabalhos do Dieese/entidade sindical \\
\hline
\end{tabular}

\section{Resultados e discussão}

\section{Participação nos lucros ou resultados \\ Remuneração condicionada}

A implantação da PLR ocorreu simultaneamente à ação do empresariado e do Estado para conter os reajustes salariais em um período de crescimento do desemprego (DEPARTAMENTO INTERSINDICAL DE ESTATÍSTICA E ESTUDOS SOCIOECONÔMICOS, 2000). A pressão causada pelo medo do desemprego impõe aos trabalhadores um "terror cego" (BEYNON, 1999, p. 33) e, além de conter os salários, exerce uma permanente coação e impele o trabalhador a aceitar formas de remuneração condicionada.

A PLR foi o principal tema nas negociações coletivas nos anos 1990 (MARTINS, 2000; CARVALHO NETO, 2001), fato que prosseguiu na década seguinte, com destaque para os trabalhadores da indústria. A PLR, em 2005, foi o principal motivo das greves realizadas pelos metalúrgicos (DEPARTAMENTO INTERSINDICAL DE ESTATÍSTICA E ESTUDOS SOCIOECONÔMICOS, 2000, 2006). Além disso, a vinculação do bônus a metas e indicadores está presente em mais de 80\% dos acordos coletivos e 50\% estabelecem mais de quatro indicadores (DEPARTAMENTO INTERSINDICAL DE ESTATÍSTICA E ESTUDOS SOCIOECONÔMICOS, 2000, 2000; 2006).

Entre as montadoras instaladas no ABC, a Mercedes Benz do Brasil (MBB), um ano antes da primeira medida provisória, em 1993, foi a primeira a instituir a PLR por meio do pagamento de um valor fixo desvinculado de resultados. O acordo seguinte estabelece sua vinculação a metas de produção, qualidade e absenteísmo. Na Scania, o pagamento do bônus foi instituído em 1995-96 e, na Volkswagen do Brasil (VW), em 1996-1997 (CARVALHO NETO, 2001).

Os dados acima indicam o peso da PLR na remuneração e sua natureza condicionada ao desempenho do trabalhador na obtenção de determinados resultados e ganhos pela empresa, um importante instrumento gerencial relacionado às modalidades de gestão da força de trabalho voltado para o aumento da intensidade do trabalho.

\section{Intensidade do trabalho e gestão da força de trabalho}

A participação nos lucros ou resultados, como se depreende da própria Lei no 10.101 , é considerada uma forma de integração dos trabalhadores à empresa. No mesmo sentido, com base na experiência internacional, Corrêa e Lima (2006) relacionam a PLR com o aumento do comprometimento, do envolvimento e do esforço do trabalhador na realização de sua tarefa, o que podemos chamar de eufemismos para exploração do trabalho via aumento da intensidade do trabalho, entendida como:

aquelas condições de trabalho que determinam o
grau de envolvimento do trabalhador, seu empenho
[...] seu esforço desenvolvido para dar conta das ta-
refas a mais [...] maior dispêndio das capacidades
físicas, cognitivas e emotivas com o objetivo de ele-
var quantitativamente ou melhorar qualitativamen-
te os resultados. Em síntese, mais trabalho. (DAL
ROSSO, 2008, p. 23)

Alguns estudos nas montadoras de veículos trazem indicações da relação entre PLR e aumento da intensidade e as formas de gestão da força de trabalho. Kafrouni (2005) relaciona o sistema de remuneração da PLR com a ampliação da pressão e do comprometimento do trabalhador potencializado por sua responsabilização perante o grupo de trabalho e as metas assumidas. Segundo a autora, a "captura da subjetividade” (p. 130) seria o adicional, não contemplado na força de trabalho, incorporado ao valor dos produtos que caracteriza a PLR como "um sistema de trocas para além das mercadorias” (KAFROUNI, 2005, p. 143). Essa interpretação, apesar de registrar a exigência de maior disponibilidade física e subjetiva do trabalhador - portanto, de mais trabalho - incorre em dois erros: um de cunho teórico e outro histórico. Em termos teóricos, o equivoco está em descolar a capacidade de trabalho (biológica e psíquica) da pessoa do trabalhador, além de reduzi-la a simples execução de atividades mecânicas. O "fazer" e o "ser" aparecem separados como duas totalidades opostas e excludentes que não estabelecem relação (contraditória) entre si. No plano histórico, o erro está em, por um lado, pressupor a incorporação da subjetividade do trabalhador como exclusividade do 
atual período do capitalismo. De outro, sugerir que ela ocorra de forma plena, sem a situar no âmbito da luta do capital pelo uso - nunca completado - da força de trabalho no processo produtivo. Infinita em potencial, mas limitada em sua concretização pela resistência dos trabalhadores (BRAVERMAN, 1987).

Campinho (2009) relaciona PLR e alterações nas formas de subordinação do trabalho ao capital, como o deslocamento da vigilância minuciosa para o controle baseado em metas por meio do trabalho em grupo. Assim, a PLR se insere entre os mecanismos desenvolvidos pelas gerências para, segundo Castro (1996, p. 27):

superar a dependência manifesta pela nova organização da produção [...] em face do desempenho e cooperação ativa dos trabalhadores.

A redução dos estoques aliado ao número mínimo de trabalhadores torna o processo de produção mais tenso. Essa maior tensão é a base objetiva em que o capital exerce a supervisão por meio da interação e do controle recíproco entre trabalhadores (CIPOLLA, 2005).

As empresas incorporaram o estresse como instrumento de gestão, a "administração por estresse" (PARKER; SLAUGHTER, 1995), que tem por fundamento, segundo os autores, manter a pressão em todos os momentos para que as "falhas" por parte dos trabalhadores ou qualquer outro problema tornem-se imediatamente visíveis para a gerência. Esta, por sua vez, pode concentrar sua atenção nesses pontos e criar pressão adicional para sua correção.

Mais que fatores técnicos e organizacionais da produção, a gestão procura fundamentalmente proteger a divisão capitalista do trabalho dos efeitos da luta de classes (PIGNON; QUERZOLA, 2001). Nesses termos, a inserção de formas de participação está longe de ser caracterizada como autonomia. O despotismo fabril se mantém combinado com outras prescrições e dispositivos para tentar expropriar os conhecimentos dos trabalhadores. Os métodos podem mudar, mas o objetivo principal manifesto em Taylor permanece vigente, ou seja, a subordinação real dos produtores diretos ao capital. O crescimento da normatização do trabalho e de seus resultados (normas de qualidade, avaliação de desempenho), da participação e responsabilização dos assalariados com os objetivos corporativos integram as práticas de gestão adequadas à intensificação do trabalho (GOLLAC; VOLKOFF, 1996). Transformados em fator produtivo (STOTZ, 1997), os dispositivos de participação na empresa atuam para neutralizar, mesmo que parcialmente, a organização sindical dos trabalhadores nos locais de trabalho (PREVITALLI, 2006) na medida em que concorrem com os coletivos informais de trabalhadores que escapam das prescrições e estabelecem outras regras e formas de fazer. Viabilizam a eficácia produtiva, mas, ao mesmo tempo, mantêm a desconfiança da empresa (LINHART, 2007). Nesse sentido, os métodos em curso buscam uma expropriação dos espaços de autonomia relativa dos trabalhadores. Um esforço na dire- ção da prescrição da subjetividade dos trabalhadores (CARVALHO, 2002; LINHART, 2007), tentativa para suprimir destes o direito ao distanciamento em relação à racionalidade, à norma e à cultura da empresa (LINHART, 2007).

A integração da PLR como instrumento gerencial para comprometimento dos trabalhadores não é automática (BECKER; RUAS, 1997), tampouco a relação entre metas e o engajamento subjetivo no trabalho. Ela envolve, simultaneamente, comprometimento e conflito (CAMPINHO, 2009). Por outro lado, a fixação de metas e indicadores vinculados ao pagamento da PLR possibilita à gestão apresentar uma medida clara e objetiva para todos os empregados. A gestão deve evitar a atitude de indiferença e assegurar a percepção pelos trabalhadores de que seu esforço é reconhecido (MOREIRA, 2007). Nesse sentido, cresceu o número de empresas que passaram a divulgar mensalmente a aferição dos resultados condicionados à PLR (ZYLBERSTAJN, 2003a). Esse procedimento contribui para manter uma pressão contínua sobre os trabalhadores no alcance dos resultados especificados em metas e indicadores nos acordos coletivos da PLR.

\section{Metas e indicadores: uma medida objetiva da inten- sidade do trabalho}

Os dados e os resultados que apresentamos neste tópico são provenientes da análise dos Acordos Coletivos de Trabalho entre o Sindicato dos Metalúrgicos do ABC-SP e as montadoras de veículos da região, coletados pelos autores na entidade sindical dos trabalhadores. Uma relação da PLR com a intensidade do trabalho pode ser observada pelo peso e a natureza de metas e indicadores estipulados nesses instrumentos.

O valor da PLR, igual para todos os empregados (exceto Diretoria, Gerência e Supervisão), é definido com base na composição e no peso relativo dos indicadores adotado no acordo específico de cada empresa. Contudo, após a aferição, o valor pago a cada trabalhador pode diferir pela inclusão, ainda limitada, de alguma variabilidade individual na composição do bônus.

Os acordos, nos anos 2000, mantêm a predominância de metas de "Produção", "Qualidade”, "Absenteísmo" e "Segurança do Trabalho".

Na VW, o peso do indicador "Volume de produção" cresceu de 40\%, em 2001, para 70\%, em 2006, enquanto os pesos dos indicadores "Qualidade" e "Assiduidade" ou "Absenteísmo", de 40\% e 20\%, declinaram para $20 \%$ e 10\%, respectivamente. Entretanto, em 2007 e 2008, o peso do indicador "volume de produção" foi reduzido para $35 \%$ e se introduziu outro indicador, o de "horas efetivamente trabalhadas por empregado" EWH/U (sigla em inglês), também com participação de $35 \%$ do valor do bônus. Ambos indicadores passaram a compor o "Índice de produção". Os percentuais dos indicadores de "Qualidade” e "Absenteísmo", em 2007 e 2008, foram mantidos idênticos aos de 2006. Todavia, a partir de 2006, constatou-se um progressivo aumento 
de suas metas e do aprimoramento da apuração de seus resultados. Em relação à “Qualidade”, além de acrescentar outros índices (introduziu-se o índice "R/1000”, que representa o número de reparos a cada mil veículos produzidos), seus valores de referência mínimos e máximos têm sido, ano a ano, mais rigorosos. Igual tendência para o indicador "Absenteísmo", medido coletivamente, com a redução dos índices mínimo e máximo. Quanto ao aprimoramento da apuração dos resultados de "Qualidade" e "Absenteísmo", sua aferição para efeitos na PLR passou a ser realizada de janeiro a dezembro, ou seja, durante todo o ano, e não apenas em alguns meses como anteriormente.

Na Ford, o acordo para o pagamento da PLR, além dos indicadores de "Qualidade" e "Volume de produção", cada um com peso de 35\% e 30\%, respectivamente, estabelece ainda os indicadores de "Segurança do Trabalho", medida pelo "Índice de Comportamento Seguro" (ICS), peso de 31\%, e de "HouseKeeping / 5 S's", apurado pela auditoria realizada nos grupos de trabalho para verificação da qualidade do ambiente de trabalho em termos de limpeza, otimização dos espaços físicos e organização do local de trabalho, com peso de 4\%. Não está previsto indicador de "Absenteísmo".

Na MBB, a meta de "Volume de produção", medido pela quantidade de caminhões, ônibus, câmbios e motores produzidos no ano, respondeu por 90\% do valor da PLR em 2008. As metas de "Qualidade", "Absenteísmo" ou "Adicional de incentivo à presença" e o "Adicional de incentivo à presença em jornadas adicionais", foram todas consideradas "metas adicionais" para complementar o valor do bônus. Contudo, o acordo estabelece sanções monetárias para restringir o absenteísmo mediante a redução do valor individual da PLR de cada trabalhador por falta injustificada praticada. O valor a ser descontado por cada falta é diferenciado e aumenta conforme sua reincidência.

Os acordos na Ford e na MBB estabelecem um valor adicional acrescido ao pagamento da PLR pelo comparecimento às "jornadas adicionais", isto é, pelo trabalho realizado em jornadas extras aos sábados ou domingos. Na MBB, somente faz jus ao adicional o trabalhador que realizar um número mínimo de jornadas extras previamente estabelecidas. Na Ford, não existe essa exigência, sendo fixado, além de um bônus adicional, um valor para cada jornada extra efetivamente trabalhada. Com o aumento no volume de produção, as jornadas extras aos sábados, domingos e feriados tornaram-se uma prática e tema de acordos. Em 2008, na MBB foram acordadas 23 jornadas extras (sendo o mínimo de 17 jornadas trabalhadas para o recebimento do adicional na PLR) e na Ford, 12 para a fábrica de carros e 33 para a fábrica de caminhões.

As metas e os indicadores (volume de produção, qualidade e características comportamentais) escolhidos nos acordos fornecem elementos para estabelecer a relação entre PLR e intensidade do trabalho. O alcance da meta "Volume de produção" acontece simultanea- mente à redução absoluta do número de trabalhadores na VW: de 23.500 trabalhadores, em 1997, para menos de 13.000, em 2008, e à redução relativa dos efetivos na MBB: se o total de empregados aumentou de 10.500 , em 2000, para pouco mais de 12.000 trabalhadores, em 2008 (crescimento de quase 15\%), a produção de ônibus e caminhões, no mesmo período, cresceu de 36.000 para mais de 68.000 unidades (expansão de 87\%). O peso da intensidade do trabalho no aumento da produção, na MBB, pode ser corroborado pela manutenção da mesma estrutura produtiva, caracterizada mais por inovações organizacionais e equipamentos mais simples que por automação (BRESCIANI, 2001).

Os acordos evidenciam também o peso dos indicadores de "Absenteísmo" e "Segurança do Trabalho". O controle (e a redução) do absenteísmo, um dos elementos moleculares de resistência massiva dos trabalhadores, tornou-se um imperativo nas empresas que operam com ajustado efetivo de trabalhadores. As metas de absenteísmo são consideradas em conjunto, estipuladas e aferidas distintamente para horistas e mensalistas significando o exercício de um constrangimento coletivo sobre o trabalhador individual. Mas, em alguns acordos, esse constrangimento é complementado com o controle do absenteísmo individual; um determinado valor é descontado da PLR do trabalhador para cada falta não justificada. O trabalhador é pressionado a não afastar-se do trabalho, inclusive a retardar a procura por cuidados com sua saúde, um elemento adicional para o aumento do presenteísmo.

Os acidentes trazem a possibilidade de afastamento temporário ou permanente dos trabalhadores e, no limite, demandaria contratação. Além da suspensão imediata, os acidentes podem dificultar o retorno do engajamento ativo dos trabalhadores na produção por ameaçar romper os mecanismos de defesa utilizados na minimização dos riscos explorado pela gerência para aumentar a produtividade (DEJOURS, 1992). A presença e o peso de um "Índice de Comportamento Seguro" do indicador "Segurança do Trabalho", na Ford, aponta que a PLR é inserida entre os mecanismos gerenciais para culpabilizar os trabalhadores pelos acidentes.

Nos indicadores de qualidade está a diminuição do retrabalho. Tarefas de melhoria e controle da qualidade são transferidas para os trabalhadores no próprio ato laboral e disseminadas em todos os níveis, setores e etapas do processo produtivo. Mesmo de forma diferenciada, atribui-se responsabilidade a cada trabalhador individual, exigindo sua maior atenção e concentração nas operações o que lhe requisita aumento das energias físicas e mentais.

Isso aparece na alteração das formas de subordinação do trabalhador. Se, por um lado, assiste-se à redução dos níveis hierárquicos e da vigilância explicita sobre o trabalhador individual, por outro, em todo o processo, cada operação realizada é identificada e o setor/área/ trabalhador individual, responsabilizado em caso de "não conformidade" à norma de qualidade. Controle de 
qualidade e, ao mesmo tempo, implicitamente, da avaliação do trabalhador.

Nesses termos, a vinculação da PLR a metas como as apresentadas neste tópico pode ser considerada uma "gestão por objetivos" e "fonte poderosa de intensificação ou de estresse” (MARC BÁRTOLI; MICHEL ROCCA apud DAL ROSSO, 2008, p. 157). Desse modo, as metas e os indicadores materializam os procedimentos da gestão utilizados na prescrição, na administração e na avaliação dos trabalhadores, além de representar uma medida objetiva da intensidade do trabalho determinante do desgaste operário.

\section{PLR e mais-valia}

Para obter o bônus, o trabalhador deve fornecer uma maior quantidade e/ou uma melhor qualidade de trabalho, o que representa maior dispêndio de suas energias físicas e mentais. É o que se depreende de Cipolla (2007), que relaciona a PLR ao aumento da intensidade do trabalho. Apesar da justeza da afirmação, o autor equivoca-se ao situar a questão em termos de mais-valia extra. Esta, segundo Marx (1984a), resulta do desenvolvimento da força produtiva do trabalho, dos métodos (novos ou aperfeiçoados) de produção que permitem a um capitalista apropriar-se de uma parte maior do trabalho excedente em comparação aos demais capitalistas do mesmo ramo. A generalização da PLR nas empresas desse ramo anularia essa possibilidade.

Mantida inalterada a jornada, o aumento na grandeza intensiva do trabalho relativa ao alcance das metas à PLR se corporifica em um número maior de produtos-valor. Por conseguinte, podemos considerar a relação entre essa forma de remuneração e a mais-valia. Ou melhor, especificamente no âmbito da relação entre as mudanças de magnitude do preço da força de trabalho e a mais-valia, estudada por Marx n'O Capital (1984b), essas magnitudes dependem da duração da jornada, da intensidade do trabalho e da força produtiva do trabalho. Interessa-nos especialmente a situação em que, mantidas constantes a jornada e a força produtiva, a intensidade do trabalho varie. No caso de intensidade do trabalho crescente:

O preço da força de trabalho e a mais-valia podem ambos crescer ao mesmo tempo de 3 para 4 xelins, se o produto-valor sobe de 6 para 8 . Aumento do preço da força de trabalho não implica aqui, necessariamente, elevação de seu preço acima de seu valor. Ele pode, pelo contrário, ser acompanhado por uma queda abaixo de seu valor. Isso ocorre sempre que o aumento do preço da força de trabalho não compensa seu desgaste acelerado. (MARX, 1984b, p. 117)

Façamos aqui uma ponderação relevante pela implicação da PLR no processo de desgaste operário e as condições de reprodução da força de trabalho. Com base na citação acima, uma elevação no preço da força de trabalho pode não compensar o desgaste do trabalhador submetido à jornada mais intensa.

Além disso, essa forma de remuneração traz outro agravante ao processo de desgaste. $\mathrm{O}$ pagamento do bônus é realizado anualmente, em uma ou duas parcelas. O trabalho mais intenso acontece em jornada diária, semanal, mensal durante todo o ano, enquanto o preço da força de trabalho pago mensalmente é mantido com base na jornada de intensidade normal. Para Cipolla (2007, p. 621):

isso significa que durante o ano os trabalhadores recebem abaixo do valor de sua força de trabalho. Na verdade, financiam o capital circulante da empresa com uma fração de seu fundo de subsistência anual.

Portanto, o acréscimo no preço da força de trabalho propiciado pela PLR - e isso independe do valor do bônus - não compensa o desgaste operário, pois ao longo do ano os trabalhadores recebem abaixo do valor de sua força de trabalho. O desgaste é agravado pela defasagem entre a realização cotidiana da atividade de trabalho mais intensa e o pagamento do bônus efetivado anual ou semestralmente.

Por sua vez, nos últimos anos, o salário foi contido, seu crescimento não acompanhou igualmente percentual de incremento da produção ou, inclusive, foi reduzido pela rotatividade praticada nas montadoras. Nesse caso, registra-se a seletividade no processo de desligamento que, em sua maioria, atinge trabalhadores com salários mais elevados.

Entre os elegíveis para o desligamento estão os trabalhadores avaliados como de "baixo desempenho" e os afastados pelo INSS (neste caso, a demissão é programada para o retorno do afastamento e a rescisão do contrato somente poderá ser realizada por acordo com anuência do sindicato: a convenção coletiva dos metalúrgicos do ABC assegura estabilidade até a aposentadoria aos trabalhadores afastados pelo INSS por acidente de trabalho ou doença profissional).

O trabalhador aposentado tem sido alvo preferencial nos desligamentos. Alguns acordos coletivos fixam um prazo limite de permanência desses trabalhadores na empresa contado a partir da concessão da aposentadoria, ou seja, os aposentados são "calendarizados para desligamento".

A redução salarial por meio da rotatividade é observada quando se constata a admissão de trabalhadores, em sua maioria jovens, predominantemente via "contrato de trabalho por prazo determinado". Nessa modalidade, o salário inicial é inferior ao piso praticado na empresa, e o trabalhador somente atinge este patamar após completar um determinado período do contrato ou ser efetivado. Além de representar uma forma de redução salarial, esse mecanismo aumenta o tempo de progressão para o trabalhador atingir as faixas salariais superiores.

A tendência de contenção salarial combinada com o aumento da intensidade do trabalho agrava o desgaste operário e as condições de reprodução da força de trabalho, remunerada durante o ano com valor inferior ao necessário a sua reprodução, em especial, quando se considera as montadoras com padrões similares de gestão e organização produtiva, mas com níveis sala- 
riais inferiores e reconhecidamente de menor organização sindical. Por exemplo: a remuneração do trabalhador (horista) em Sete Lagoas/MG e em Camaçari/BA representa $1 / 4$ e $1 / 3$, respectivamente, da remuneração do trabalhador na mesma função na Região do ABC (DEPARTAMENTO INTERSINDICAL DE ESTATÍSTICA E ESTUDOS SOCIOECONÔMICOS; SINDICATO DOS METALÚRGICOS DO ABC; CONFEDERAÇÃO NACIONAL DOS METALÚRGICOS DA CUT..., 2003).

A PLR expõe um indicador do desgaste operário ao excluir do pagamento do bônus segmentos dos trabalhadores afastados pelo INSS. Os acordos coletivos, por nós analisados, excluem do pagamento integral do bônus os trabalhadores afastados por auxílio doença com data de afastamento anterior ao início do ano base do acordo ou por acidente de trabalho ou doença profissional com data de afastamento anterior a 12 meses do primeiro dia do ano base, desde que, em ambos os casos, não retornem à atividade na empresa no decorrer do ano do acordo. Para os demais casos, conforme o acordo coletivo de cada montadora, o pagamento do bônus poderá ser integral ou proporcional.

Para o alcance dessa forma de remuneração a cada novo período, novas metas e/ou indicadores são definidos ou aprimorados e um novo desempenho, conhecido ou não, é requerido do trabalhador - uma condição geradora de insegurança (LASSANCE MOREIRA, 2007). A situação de trabalho e remuneração condicionada a metas é impregnada de ansiedade, medo, tensão pelo temor de não acompanhar o ritmo, de não atingir as metas de produção e qualidade requeridas, de ser negativamente avaliado no limite considerado como de "baixo desempenho" - todos esses elementos são determinantes do desgaste e de um contínuo esgotamento do trabalhador (DEJOURS, 1992).

Como vimos, a PLR exerce maior pressão sobre o trabalhador para o aumento quantitativo e qualitativo do trabalho, o que representa a elevação da intensidade e do desgaste operário. Outros mecanismos, como a gestão do tempo de trabalho via banco de horas, acentuam o processo de intensificação do trabalho como veremos a seguir.

\section{Banco de horas}

O regime de compensação de horas conhecido como banco de horas, objeto de regulação estatal por meio da Lei n⿳o 9.601 de janeiro de 1998, constituiu uma das alterações mais significativas relativa ao tempo de trabalho. A jornada de trabalho diária pode ser ampliada ou reduzida e as horas trabalhadas a mais ou a menos são contabilizadas como positivas ou negativas no banco de horas. A lei limitou em duas horas o número excedente de horas diárias destinadas para futura compensação, sem acréscimo no salário. Inicialmente, a compensação das horas deveria ocorrer no período de cento e vinte dias. Posteriormente, a Medida Provisória $\mathrm{n}^{\mathrm{o}}$ 2.164-41, de 24 de agosto de 2001, estendeu esse prazo para um ano. Denominado por alguns de sis- tema de horas anualizadas (MARÇOLA; GONÇALVES FILHO; FERNANDES, 2002), o banco de horas deve ser objeto de acordo ou convenção coletiva de trabalho entre trabalhadores e empresa. Esse dispositivo introduz modificações em termos quantitativos e qualitativos na gestão e organização do tempo de trabalho e, inclusive, do tempo de não trabalho.

\section{Organização do tempo de trabalho}

A adoção do banco de horas surge como uma das formas de flexibilizar a jornada de trabalho, às vezes aliada à sua redução. Por isso, o debate internacional sobre a flexibilidade faz referência à "redução-reorganização" do tempo de trabalho (BOULIN; TADDEI, 1991; DEPARTAMENTO INTERSINDICAL DE ESTATÍSTICA E ESTUDOS SOCIOECONÔMICOS, 1997). No Brasil, entre outubro de 1994 e maio de 1998, dos 52 acordos e convenções coletivos de trabalho analisados pelo Dieese (DEPARTAMENTO INTERSINDICAL DE ESTATÍSTICA E ESTUDOS SOCIOECONÔMICOS, 2002), 35 previam a redução da jornada. Desses, 11 vinculavam a redução à sua flexibilização. O Sindicato dos Metalúrgicos do ABC (1993) foi um dos pioneiros a trilhar essa diretriz para conquistar a redução da jornada nas montadoras da Região. Na Ford, na VW e na MBB, a partir de janeiro de 1996, a jornada foi reduzida de 44 para 43 horas semanais (horistas) e, em outubro do mesmo ano, para 42 horas. Na Scania, a jornada foi reduzida a 40 horas desde o início daquele ano (BRESCIANI, 1997). Em 2000 , todas as montadoras reduziram a jornada para 40 horas. A Ford, em setembro de 1995, e a VW, em janeiro de 1996, foram as primeiras a flexibilizarem a jornada por meio do banco de horas, em seguida adotado pelas demais.

A reorganização do tempo de trabalho trouxe algumas mudanças nas relações de trabalho. As horas de atrasos, saídas antecipadas e faltas injustificadas podem ser negociadas e debitadas do banco de horas, sem perda do descanso semanal remunerado (DSR) e descontos nas férias. O DSR, assim, perde força como instrumento de controle do trabalhador (BLASS, 1998).

Por outro lado, a legislação ao, estabelecer o limite diário de duas horas com compensação anual, possibilitou a contínua prorrogação da jornada de trabalho, uma questão controversa no âmbito do Direito do Trabalho. O questionamento tem por base a agressão à saúde do trabalhador submetido a longo período (anual) de prorrogação de horário. Alguns juristas, inclusive, sustentam a inconstitucionalidade do $\S 2^{\mathrm{o}}$ do artigo 59 da Consolidação das Leis do Trabalho (CLT) (ABUD, 2008).

A lei não impõe limite mínimo nem máximo de horas no banco. Esse e outros aspectos, como a variação semanal da jornada e os critérios para compensação das horas, passam a ter importância nas negociações. O Quadro 2 apresenta esses elementos segundo algumas empresas selecionadas. 
Quadro 2 Banco de horas: algumas cláusulas dos acordos coletivos dos metalúrgicos do ABC-SP, segundo a montadora selecionada

\begin{tabular}{|c|c|c|c|c|}
\hline \multirow{2}{*}{ Empresa } & \multirow{2}{*}{$\begin{array}{l}\text { Variação semanal } \\
\text { da jornada (h) }\end{array}$} & \multirow{2}{*}{$\begin{array}{l}\text { Lançamento das horas no } \\
\text { banco }\end{array}$} & \multicolumn{2}{|c|}{ Compensação do saldo e limites de horas no banco } \\
\hline & & & Positivo & Negativo \\
\hline Volkswagen & $\begin{array}{l}\text { Mínima: } 34 \\
\text { Máxima: } 44\end{array}$ & $\begin{array}{l}\text { Se o saldo estiver posi- } \\
\text { tivo: Crédito de } 50 \% \text { até } \\
\text { o limite de } 40 \mathrm{~h} \text {. mensais } \\
\text { e } 150 \mathrm{~h} \text { em } 12 \text { meses. As } \\
\text { demais ( } 50 \% \text { ) são pagas } \\
\text { com o adicional. } \\
\text { Se o saldo estiver nega- } \\
\text { tivo: todas as horas vão } \\
\text { para o Banco e paga-se } \\
\text { apenas o adicional. }\end{array}$ & $\begin{array}{l}\text { Limite: não prevê } \\
\text { Durante o período: Folgas } \\
\text { seguidas às férias individuais } \\
\text { ou coletivas; folgas coletivas; ou } \\
\text { folgas individuais negociadas. } \\
\text { Ao término do período de } 12 \\
\text { meses: Até } 24 \text { h folgas gozadas } \\
\text { com as férias. Do saldo restante, } \\
50 \% \text { será transferido para o } \\
\text { exercício seguinte. As horas dos } \\
50 \% \text { restantes serão pagas. }\end{array}$ & $\begin{array}{l}\text { Limite de } 120 \text { h. } \\
\text { Durante o período: Convocação } \\
\text { para trabalhar, inclusive aos } \\
\text { sábados, da seguinte forma: } \\
\text { individual com no mínimo } 24 \text { h } \\
\text { de antecedência, ou coletiva, até } \\
\text { a sexta-feira que antecede ao } \\
\text { trabalho. } \\
\text { Ao término do período de } 12 \\
\text { meses: As horas são transferidas } \\
\text { para o exercício seguinte. }\end{array}$ \\
\hline Ford & $\begin{array}{l}\text { Mínima: } 38 \\
\text { Máxima: } 45\end{array}$ & - & $\begin{array}{l}\text { Folgas individuais ou coletivas, } \\
\text { ou pagas como hora extra. }\end{array}$ & $\begin{array}{l}\text { Horas transferidas para o } \\
\text { próximo período }\end{array}$ \\
\hline $\begin{array}{c}\text { Mercedes } \\
\text { Bens }\end{array}$ & $\begin{array}{l}\text { Mínima: - } \\
\text { Máxima: } 45\end{array}$ & $\begin{array}{l}\text { Crédito de } 15 \text { a } 60 \text { minu- } \\
\text { tos / dia. } \\
\text { Exclui as horas extras } \\
\text { aos sábados, domingos } \\
\text { e feriados, pagas com } \\
\text { adicionais. }\end{array}$ & $\begin{array}{l}\text { Limite: } 120 \mathrm{~h} \\
\text { Folgas individuais ou coletivas, } \\
\text { ou horas transferidas para o } \\
\text { próximo período }\end{array}$ & $\begin{array}{l}\text { Limite: } 120 \mathrm{~h} \\
\text { Horas transferidas para o próximo } \\
\text { período }\end{array}$ \\
\hline
\end{tabular}

Fonte: Sindicato dos metalúrgicos do ABC (2001); Sindicato dos metalúrgicos do ABC; Volkswagem do Brasil Ltda. (2006, 2007); Sindicato dos metalúrgicos do ABC; Ford Motor Company Brasil Ltda. (2008); Manzano (2004).

Os acordos coletivos de compensação por meio do banco de horas incluem a possibilidade do trabalhador utilizar as horas como folga se o saldo estiver positivo ou negativo, desde que até determinado limite. Apesar disso, a compensação das horas positivas em folgas nem sempre é efetivada e, como podemos perceber pelo Quadro 2, a empresa pode converter o saldo em pagamento de horas extras ou mesmo o transferir para o próximo exercício do banco de horas.

A constante possibilidade de convocação para trabalho extra, variações nos horários de trabalho e com pouca antecedência dificulta a programação do tempo fora do local de trabalho, dificuldade agravada pela insuficiente autonomia dos trabalhadores para decidir quando usar o banco de horas. Esse ponto pode variar segundo a empresa. Mas a folga para uns representa a incorporação de mais trabalho para os demais integrantes do grupo que assumem as tarefas de quem folga, um elemento comum à gestão nas montadoras com plantas industriais em outros países (STEWART et al., 2006). Em geral, a empresa determina tanto o período de convocação para trabalho adicional, quanto o momento para sua compensação (CARDOSO, 2009). Conforme o estudo de Janssen e Nachreiner (2004), a variabilidade do horário de trabalho flexível acarreta um maior prejuízo à saúde e ao bem-estar psicossocial.

\section{Jornada de trabalho e desgaste operário}

No Brasil persiste a tendência de prolongamento da jornada semanal de trabalho legalmente estabelecida (FREITAS, 2006). A hora extra se mantém como um dos instrumentos mais utilizados pelas empresas para sustentar a expansão econômica. A redução da jornada para 44 horas semanais foi acompanhada de uma significativa elevação dos assalariados que, habitualmente, realizam hora extra. Se até a Constituição de 1988, aproximadamente 25\% dos trabalhadores assalariados da Região Metropolitana de São Paulo realizavam hora extra, após sua promulgação, a proporção aumenta para cerca de $40 \%$ e esse índice, com pequenas variações, mantém-se até hoje (DEPARTAMENTO INTERSINDICAL DE ESTATÍSTICA E ESTUDOS SOCIOECONÔMICOS, 2009). Os ramos metalúrgico e químico se destacam pela alta concentração de trabalhadores em exercício de hora extra, 68,5\% e 60,7\%, respectivamente (CENTRAL ÚNICA DOS TRABALHADORES; DEPARTAMENTO INTERSINDICAL DE ESTATÍSTICA E ESTUDOS SOCIOECONÔMICOS, 2006).

Um ponto a destacar é a relação entre banco de horas e hora extra. Contrariando a expectativa, conforme apontado por Blass (1998), na "dimensão pedagógica" do banco de horas para restringir as horas extras, esse 
dispositivo mais apropriadamente reforça a tentativa de desconstrução da "idéia de trabalho extraordinário" e da delimitação entre jornada habitual e jornada extraordinária (SOCHACZEWSKI, 2007, p. 9). Segundo a autora:

a fronteira entre os dois exercícios de trabalho se apaga quando se enquadra o conjunto total de horas em um outro marco conceitual. (p. 13)

Ou seja, uma concepção contábil da jornada de trabalho: horas a mais (positiva) e horas a menos (negativa). No Brasil, em $77 \%$ das empresas que adotam o banco de horas, a compensação ocorre na base de uma hora a mais por uma hora a menos, ou seja, trabalho extraordinário sem acréscimo de adicional compensado por horas da jornada normal (ZYLBERSTAJN, 2003b).

A partir de 2000, a jornada nas montadoras do ABC foi reduzida para 40 horas semanais, mas o banco de horas possibilitou manter a jornada acima desse patamar. Como é possível perceber pelo Quadro 2, a jornada de trabalho diária durante todo o ano é acrescida de horas (ou fração) a mais creditadas como positivas no banco de horas para futura compensação. Uma jornada diária prolongada pelo trabalho extraordinário passou a ser a "jornada habitual". Portanto, o banco de horas atua como instrumento para prolongar a jornada e coloca em questão os efeitos positivos obtidos com a conquista de sua redução.

Por outro lado, a relação entre flexibilização do tempo e intensidade do trabalho é destacada em vários estudos (CALVETE, 2006; CARDOSO, 2009; FERREIRA, 2004; KREIN, 2007). O banco de horas se relaciona ao processo de conversão do máximo tempo de trabalho em trabalho produtivo por meio da combinação entre prolongamento da jornada e aumento da intensidade do trabalho. Essa condição pode ultrapassar o limite suportável pela força de trabalho.

Nas condições de produção enxuta, as empresa operam com o mínimo de trabalhadores e a compensação de hora a mais por hora a menos representa o movimento do capital para viabilizar a continuidade ininterrupta dos turnos/tempos de trabalho, assegurar o funcionamento contínuo da empresa e eliminar ou diminuir a porosidade existente na jornada: "fragmentos", "átomos" ou "coágulos" de tempo de trabalho não convertidos em trabalho produtivo, produtor de mais-valia (MARX, 1984a; 1984b). A metáfora da porosidade dá a ideia simultaneamente física/abstrata, e biopsíquica/concreta, de que o tempo de trabalho tem densidade, compreende continuidades/descontinuidades e também aberturas/fechamentos: por meio dos "poros", o trabalhador "respira na ação", no tempo em que trabalha, torna-o mais ou menos denso.

A menção às horas trabalhadas a mais e a menos para efeitos de compensação atua para dissolver a diferença qualitativa entre os tempos. A conversão contábil das horas a mais por igual quantidade de horas a menos (folgas) tenta nublar o fato do trabalho na hora a mais, como o próprio nome sugere, ocorrer pelo prolongamento da jornada, ou seja, pelo trabalho extraordinário - transformado em jornada habitual - de maior desgaste.

Em momentos de diminuição na produção, as empresas recorrem ao banco de horas para conceder "folgas coletivas” à parcela de seus empregados. Estabelecem o uso adequado entre o nível de produção e uma determinada quantidade de trabalhadores na fábrica. Esse procedimento atua no sentido de manter elevado o grau da intensidade do trabalho independentemente das flutuações no volume de produção.

Isso se coaduna com a "administração por estresse”, que mantém os trabalhadores sob pressão contínua, procura evitar o surgimento de "folgas" e, ao mesmo tempo, remover ou reduzir qualquer uma delas, especialmente aquelas que os trabalhadores conseguem criar para si mesmos durante a jornada (PARKER; SLAUGHTER, 1995). Segundo relato de comissários de fábricas, a "administração por estresse" já faz parte inclusive do perfil do trabalhador na indústria automobilística: bom relacionamento, trabalho sob pressão e visão sistêmica são algumas das "qualificações" requeridas (STOTZ et al., 2009).

Também aqui, de forma similar ao considerado para a PLR, a remuneração das horas em regime de compensação por banco de horas pode ser analisada no âmbito da relação entre as mudanças de magnitude no preço da força de trabalho e a mais-valia. Nesse caso, temos simultaneamente combinados o aumento da grandeza extensiva e da grandeza intensiva do trabalho, ambas corporificando um número maior de produtos-valor. Essa combinação eleva e potencializa as cargas de trabalho e o desgaste do trabalhador, tanto mais pelo fato da compensação das horas ocorrer na base de uma hora a mais por uma hora a menos. Ou seja, a hora a mais, de maior desgaste, é remunerada pelo preço da força de trabalho com base na hora normal, portanto, uma remuneração inferior ao valor da força de trabalho necessário à sua reprodução social (média).

Além disso, como o pagamento da hora a mais somente é efetivado no momento da compensação das horas, ou seja, com a utilização das folgas, esse período pode se estender até um ano depois das horas trabalhadas a mais, ou a um intervalo ainda maior, caso o saldo positivo no banco de horas seja transferido para o próximo exercício. Assim, o pagamento da hora a mais (de maior desgaste), além do preço inferior ao valor da força de trabalho, pode ocorrer em período superior a um ano. Seguramente, durante o ano, os trabalhadores com saldo positivo no banco de horas recebem abaixo do valor de sua força de trabalho e assim se mantêm, continuamente, com a renovação anual desse regime de compensação de horas.

Por outro lado, o banco de horas produz alterações na qualidade do tempo fora da jornada de trabalho. Segundo Paixão (2005), mesmo um trabalho não realizado encontra-se antecipadamente apropriado pelo capital na forma de horas negativas no banco de horas, com isso, "a jornada de trabalho perde a sua delimita- 
ção” (p. 164). Esta formulação pode levar a equívocos e a perder de vista a contradição entre os dois momentos. $\mathrm{O}$ autor faz alusão à relação entre o tempo de trabalho e o tempo de não trabalho fora da jornada, mas por meio de uma ilusão, visto que, ao diluir ou extinguir a delimitação entre os dois diferentes momentos, elimina-se a própria relação entre eles. É preciso então reconhecer a existência do tempo de trabalho e do tempo de não trabalho como dois pólos opostos que estabelecem relação mútua de um com o outro enquanto unidade contraditória, de subordinação do trabalho ao capital. Nesse sentido, seria mais apropriado falar em relação de determinação recíproca, em que a empresa capitalista amplia a dominação do tempo de trabalho sobre o tempo de não trabalho.

A hora a menos na forma de folgas coletivas ou individuais definidas pela empresa, a exemplo dos períodos de baixa produção ou crise, está longe de configurar condição de repouso, descanso ou lazer para os trabalhadores. Pelo contrário, agora sobreposto às estratégias defensivas para manter pelo condicionamento produtivo (DEJOURS, 1992), pode representar aumento da tensão, da ansiedade e da insegurança decorrente da expectativa pelo retorno ou pelo desligamento do trabalho. Um tempo de "não trabalho", mas sem se distanciar do trabalho, tempo de insegurança, tensão, ansiedade, ou seja, de aumento do desgaste mental pela ampliação da determinação/dominação do tempo de trabalho.

Também é bom frisar que a adoção do banco de horas, assim como da PLR, ocorre e integra um conjunto de alterações no processo de trabalho imediato. Para introdução da multitarefa ou do revezamento de função, a gerência alegou a prevenção de problemas de saúde decorrentes do trabalho repetitivo e monótono pelo exercício cotidiano da mesma função (CARDOSO, 2009). Contudo, a rotação de funções aumentou o ritmo de trabalho: a empresa pode deslocar o trabalhador da função/área/setor, momentaneamente, com menor demanda para aquele de maior produção. Assim, tanto os que estão no exercício da rotação de função estão submetidos ao trabalho mais intenso, quanto os que permanecem na função/área/setor por absorverem as atividades dos trabalhadores transferidos. A multifuncionalidade ou polivalência, em muitos casos, mantém condições de trabalho desqualificadas e vazias de conteúdo e, principalmente, introduz novas formas de despojar os trabalhadores de suas condições de defesa coletiva e afeta as possibilidades de proteção das nocividades do processo de trabalho (VILLEGAS et al., 1997). Os trabalhadores em rotação de funções, segundo Dejours (1992), são confrontados com extensão das cargas de trabalho, aumento da tensão nervosa, medo e casos de descompensação.

A rotação mantém ou acentua a pressão exercida pelo tempo alocado para execução da tarefa ou pelo tempo imposto para os trabalhadores transferidos para uma linha de montagem; para estes, segundo Cardoso (2009, p. 205-206): é a combinação do banco de horas com a multitarefa que tem levado à extrema intensificação [...] leva o trabalhador a estar sempre no momento - em função do banco de horas -, e no espaço - dada à multitarefa -, onde há maior demanda de produção.

Apoiando-se em Cardoso (2009), Previtalli (2006) e Sales (2002), é possível indicar que essa e outras alterações na organização do trabalho (células de produção, redução da duração e da quantidade de pausas individuais e coletivas, diminuição do tempo para realização de cada tarefa e do intervalo entre uma tarefa e outra) aliadas ao aumento da pressão pela contínua melhoria da qualidade configuram um processo de intensificação do trabalho.

O prolongamento e a intensificação do trabalho parecem anular as vantagens obtidas com a conquista da redução da jornada de trabalho, mais ainda quando o desgaste decorrente é cotejado com as dimensões do processo reprodutivo dos trabalhadores - reposição e desenvolvimento da capacidade biopsíquica nas condições concretas de reprodução da força de trabalho. A intensificação condiciona e limita a qualidade do tempo fora da jornada utilizado, majoritariamente, como alívio de tensões, reposição de necessidades básicas: dormir, descansar, repor as energias físicas e mentais (CARDOSO, 2009). Para um contingente cada vez mais numeroso de trabalhadores, a reposição está ainda mais comprometida pelo tempo e pela energia despendidos no estudo/formação e nos deslocamentos residência-trabalho/estudo-residência. A reposição biopsíquica é particularmente necessária em processos de intensificação do trabalho. A combinação de longas horas de trabalho e processos cognitivos relacionados ao estresse dificulta a reposição biopsíquica, prolonga a ativação fisiológica e resulta no aumento da "carga alostática", um caminho aberto para os problemas crônicos de saúde (GEURTS; SONNENTAG, 2006). Importante ainda considerar a diferenciação dos processos de desgaste e reprodução social dos trabalhadores em regime de banco de horas: o desgaste operário tende a ser potencialmente maior no trabalho em turnos de revezamento (FERREIRA, 2004).

Se para a empresa, o estresse se torna instrumento de gestão; para os trabalhadores, ele configura um problema de saúde inseparável das formas de expressão e resistência dos trabalhadores. A greve dos trabalhadores da Volkswagen-Audi - PR, em maio de 2004, segundo Penkal (2005, p. 41):

teve como principal causa, não a PLR e o banco de horas, mas o ritmo intenso de trabalho. Os trabalhadores utilizaram a greve para ganhar um fôlego. A paralisação ocorreu em função da insatisfação com as condições de trabalho e a pauta de negociação da greve foi apenas uma forma de dar caráter reivindicatório e palpável à direção da empresa.

Objetivamente, a resistência dos trabalhadores estabelece uma relação entre os instrumentos de gestão, como a PLR e, mais acentuadamente, o banco de horas, de um lado, e a intensificação do trabalho e o des- 
gaste operário, de outro. Assim, esses instrumentos de gestão podem configurar situações de trabalho de alta exigência (e consequente desgaste) para o trabalhador, o que, segundo estudos da epidemiologia social, é um terreno para o estresse e o adoecimento relacionados ao trabalho (ARAÚJO; GRAÇA; ARAÚJO, 2003; KARASEK; THEORELL, 1990).

\section{Considerações finais}

Neste artigo discutimos as formas de gestão da força de trabalho pondo em evidência a participação nos lucros ou resultados (PLR) e o banco de horas como instrumentos gerenciais para extrair mais trabalho dos trabalhadores por meio do prolongamento e do aumento da intensidade do trabalho ou pela ação simultânea de ambos. Essa ação combinada eleva e potencializa as cargas de trabalho e o desgaste do trabalhador.

Os dois mecanismos promovem alterações na forma de remuneração do trabalhador, aumentando o desgaste operário do ponto de vista do valor social médio da força de trabalho. Mesmo o acréscimo no preço da força de trabalho - efetivado pela PLR, mas não pelo banco de horas - não compensa o maior desgaste advindo do aumento da grandeza extensiva e da grandeza intensiva do trabalho. Esse desgaste é tanto mais agravado pela defasagem entre a realização cotidiana da atividade de trabalho e o período do efetivo pagamento implicado pelos dois mecanismos, de modo que, durante o ano, os trabalhadores recebem abaixo do valor de reprodução da força de trabalho.

Por sua vez, a PLR e o banco de horas integram-se na organização capitalista do trabalho com base na administração por estresse. A PLR condicionada a metas materializa procedimentos da gestão utilizados na prescrição, na administração e na avaliação dos trabalhadores e representa uma medida objetiva da intensidade do trabalho determinante do desgaste operário. O regime de compensação de horário na modalidade banco de horas introduz modificações na gestão e na organização do tempo de trabalho. Viabiliza a conversão da jornada prolongada acrescida da hora extraordinária em “jornada habitual" e mantém elevado o grau de intensidade do trabalho independentemente da flutuação da produção.

O prolongamento e a intensificação do trabalho empreendem, simultaneamente, a dilatação do tempo de trabalho e a diminuição do tempo de não trabalho durante a jornada, ambos determinantes do desgaste operário. No mesmo processo, ampliam os condicionantes e os limites do tempo de não trabalho fora da jornada: a reposição e o desenvolvimento de capacidades biopsíquica podem ser comprometidos pela insuficiente quantidade e qualidade do repouso, pela energia despendida no estudo/capacitação e nos deslocamentos residência-trabalho/estudo-residência. Há ainda o fato de que, somente depois de um longo período, parte do tempo de trabalho já efetivado pode se expressar em tempo de não trabalho, por ocasião das folgas (individuais ou coletivas). Além disso, esse período pode compreender um permanente estado de ansiedade, tensão e insegurança pela possibilidade de convocação, retorno ou mesmo desligamento do trabalho, ou seja, um tempo gerador de desgaste mental.

Isso remete e desafia as futuras investigações a delimitarem os diversos momentos da relação recíproca de determinação do tempo de não trabalho (na/fora da jornada) pelo tempo de trabalho, assim como as implicações para a saúde dos trabalhadores segundo a especificidade do setor, ramo econômico ou empresa, especialmente nas condições de intensificação da mobilização/disputa da subjetividade do trabalhador empreendida pela administração por estresse determinante do desgaste, considerando sua dimensão integradora para a saúde mental (SELIGMANN-SILVA, 1994). Em perspectiva, estudos deste tipo podem contribuir para construção de indicadores do processo de desgaste antes do dano à saúde (LAURELL; NORIEGA, 1989), objetivamente uma questão inseparável das formas de resistência dos trabalhadores. Um desafio permanente para a Saúde do Trabalhador.

\section{Constribuições de autoria}

Pina, J. A.: responsável pela definição do marco teórico-metodológico, pelo planejamento, pela realização da pesquisa e pela análise dos resultados. Stotz, E. N.: participou da orientação geral do artigo, na redação do contexto histórico e contribuiu na estruturação e revisão do manuscrito.

\section{Referências}

ABUD, C. J. Jornada de trabalho e a compensação de horários. São Paulo: Atlas, 2008.

ANDERSON, P. Câmaras setoriais: histórico e acordos firmados - 1991/95. Brasília; DF: IPEA, setembro 1999. 45 p. (Textos para discussão, n. 667)

ARAÚJO T. M.; GRAÇA C. C.; ARAÚJO, E. Estresse ocupacional e saúde: contribuições do Modelo
Demanda-Controle. Ciência \& Saúde Coletiva, Rio de Janeiro, v. 8, n. 4, p. 991-1003, 2003.

BECKER, G. V.; RUAS, R. L. Estratégias de comprometimento e planos de participação nos lucros: tendências recentes. Revista de Administração Contemporânea, Rio de Janeiro, v. 1, n. 3, p. 141-161, 1997. 
BEYNON, H. As práticas do trabalho em mutação. In: ANTUNES, R. Neoliberalismo, trabalho e sindicatos: reestruturação produtiva no Brasil e na Inglaterra. São Paulo: Boitempo, 1999. p. 9-38.

BLASS, L. M. S. Jornada de trabalho: uma regulamentação em múltipla escolha. Revista Brasileira de Ciências Sociais, São Paulo, v. 13, n. 36, fev. 1998. Disponível em: <http://www.scielo. br/scielo.php?script $=$ sci_arttext\&pid $=$ S0102$69091998000100004 \& \operatorname{lng}=$ pt\&nrm $=$ iso $>$ Acesso em: 20 ago. 2009.

BOULIN, J.; TADDEI, D. Os acordos de reduçãoreorganização do tempo de trabalho: negociações e conseqüências econômicas. Revista de Administração de Empresas, São Paulo, v. 31, n. 2, p. 5-24, 1991.

BRASIL. Constituição da República Federativa do Brasil de 1988. Brasília, 05 de outubro de 1988. Disponível em: < http://www.planalto.gov.br/ccivil_03/ constituição/Constitui\%E7ao_Compilado.htm >. Acesso em: 15 jun. 2010.

BRAVERMAN, H. Trabalho e capital monopolista: a degradação do trabalho no século XX. 3. ed. Rio de Janeiro: Guanabara, 1987.

BRESCIANI, L. P. Na zona do agrião: a nova agenda da negociação coletiva. In: ARBIX, A.; ZILBOVICIUS, M. De JK a FHC: a reinvenção dos carros. São Paulo: Scritta, 1997. p. 257-284.

. O contrato da mudança: a inovação e os papeis dos trabalhadores na indústria brasileira de caminhões. 357 f. Tese (Doutorado em Política Científica e Tecnológica)-Instituto de Geociências, Universidade Estadual de Campinas, Campinas, 2001.

CALVETE, C. S. Redução da jornada de trabalho: uma análise econômica para o Brasil. 217 f. Tese (Doutorado em Economia Aplicada)-Instituto de Economia, Universidade Estadual de Campinas, Campinas, 2006.

CAMPINHO, F. A. R. Participação nos lucros ou resultados: subordinação e gestão da subjetividade. São Paulo: LTr, 2009.

CARDOSO, A. C. M. Tempos de trabalho, tempos de não trabalho: disputas em torno da jornada do trabalhador. São Paulo: Annablume, 2009.

CARVALHO NETO, A. Relações de trabalho e negociação coletiva na virada do milênio: estudo em quatro setores dinâmicos da economia brasileira. Belo Horizonte: Vozes; IRT; PUC/MG, 2001.

CARVALHO, R. A. A. A produção e a gestão de competências: o caso Fiat em questão. In: NABUCO, M. R.; NEVES, M. A.; CARVALHO NETO, A. M. Indústria automotiva: a nova geografia do setor produtivo. Rio de Janeiro: DP\&A, 2002. p. 241-269.

CASTRO, N. A. Modernização e trabalho no complexo automotivo brasileiro. In: CASTRO, N. A. A máquina e o equilibrista: inovações na indústria automobilística brasileira. São Paulo: Paz e Terra, 1996. p. 15-49.
CENTRAL ÚNICA DOS TRABALHADORES; DEPARTAMENTO INTERSINDICAL DE ESTATÍSTICA E ESTUDOS SOCIOECONÔMICOS. Resultado da pesquisa nacional sobre hora extra nos Ramos da CUT. In: SECRETARIA DE POLÍTICA SINDICAL DA CUT. Hora extra: o que a CUT tem a dizer sobre isto. São Paulo: CUT Brasil, 2006. p. 19-44.

CIPOLLA, F. P. Trabalho em equipe como forma da subsunção real. Estudos Econômicos, São Paulo, v. 35, n. 1, p. 203-232, 2005.

. Os limites da participação dos trabalhadores nos ganhos das empresas. Revista de Economia Política, São Paulo, v. 27, n. 4, p. 616-632, 2007. CORRÊA, D.; LIMA, G. T. Participação dos trabalhadores nos lucros e resultados das empresas: lições da experiência internacional. Revista de Economia Contemporânea, Rio de Janeiro, v. 10, n. 2, p. 357-388, 2006.

COSTA, F. H. R. Jornada de trabalho e as recentes transformações no setor bancário brasileiro. 2002. 135 f. Dissertação (Mestrado em Desenvolvimento Econômico)-Universidade Federal do Paraná, Curitiba, 2002.

DAL ROSSO, S. Mais trabalho: a intensificação do labor na sociedade contemporânea. São Paulo: Boitempo, 2008.

DEDECCA, C. S. Racionalização econômica e trabalho no capitalismo avançado. Campinas: Unicamp-IE, 1999. (Coleção Teses).

DEJOURS, C. A loucura do trabalho: estudo de psicopatologia do trabalho. 5. ed. Tradução Ana Isabel Paraguay e Lúcia Leal Ferreira. São Paulo: Cortez; Oboré, 1992.

DEMETRIADES, S.; PEDERSINI, R. Working time in the EU and other global economies. Dublin: European Foundation for the Improvement of Living and Working Conditions, 2008.

DEPARTAMENTO INTERSINDICAL DE ESTATÍSTICA E ESTUDOS SOCIOECONÔMICOS. Jornada de trabalho: lutas e história. Boletim do Dieese n. 197, agosto, 1997. Disponível em: <http://www.dieese.org.br/bol/ int/intago97.xml>. Acesso em: 02 out. 2009.

. Um balanço da participação dos trabalhadores nos lucros e resultados das empresas: 1996-1999. São Paulo: 2000. (Pesquisa Dieese, n. 16)

. A negociação da jornada de trabalho por meio do banco de horas. São Paulo: Dieese, 2002. (Kit do Seminário).

. Participação dos trabalhadores nos lucros ou resultados das empresas 2005. São Paulo: Dieese, 2006. (Estudos e Pesquisa, n. 22)

. Anuário dos trabalhadores 2009. 10. ed. São Paulo: Dieese, 2009. Disponível em: < http://www. dieese.org.br/anu/anuarioTrabalhadores2009/Arquivos/ 
ANUARIO_TRABALHADORES_2009v.pdf $>$. Acesso em: 15 mar. 2010.

DEPARTAMENTO INTERSINDICAL DE ESTATÍSTICA E ESTUDOS SOCIOECONÔMICOS; SINDICATO DOS METALÚRGICOS DO ABC; CONFEDERAÇÃO NACIONAL DOS METALÚRGICOS DA CUT. Do holerite às compras: remuneração, preços e poder aquisitivo do tempo de trabalho em 17 municípios com produção automobilística no Brasil. junho 2003. $91 \mathrm{p}$.

FERREIRA, J. O. S. A regulação pública da jornada de trabalho brasileira. 2004. 211 f. Dissertação (Mestrado)-Instituto de Economia, Universidade Estadual de Campinas, Campinas, 2004.

FREITAS, R. A. Tempo de trabalho e sindicalismo: uma análise da ação sindical na questão do tempo de trabalho (1980-2000). 2006. 205 f. Tese (Doutorado em Sociologia)-Universidade Estadual Paulista Júlio de Mesquita Filho, Araraquara, 2006.

GEURTS, S. A. E.; SONNENTAG, S. Recovery as an explanatory mechanism in the relation between acute stress reactions and chronic health impairment. Scandinavian Journal of Work Environment \& Health, v. 32, n. 6, p. 482-492, 2006.

GOLLAC, M.; VOLKOFF, S. Citius, altius, fortius: l'intensification du travail. Actes de la Recherche en Sciences Sociales, n. 114, p. 54-67, sept. 1996.

JANSSEN, D.; NACHREINER, F. Health and psychosocial effects of flexible working hours. Revista de Saúde Pública, São Paulo, v. 38, supl, p. 11-18, 2004.

KAFROUNI, M. A. S. A participação nos lucros e resultados na indústria automobilística do Paraná: um sistema de trocas para além das mercadorias. 2005. 156 f. Dissertação (Mestrado em Sociologia)Universidade Federal do Paraná, Curitiba, 2005.

KARASEK, R.; THEORELL, T. Healthy work: stress, productivity, and the reconstruction of working life. New York: Basic Book, 1990.

KREIN, J. D. Tendências recentes nas relações de emprego no Brasil: 1990-2005. 2007. 329 f. Tese (Doutorado em Economia)-Universidade Estadual de Campinas, Campinas, 2007.

LASSANCE MOREIRA, V. S. Dobras da subjetividade: a remuneração variável como caso-pensamento do contemporâneo. Psico, Porto Alegre, v. 38, n. 1, p. 95106, jan./abr. 2007.

LAURELL, A. C.; NORIEGA, M. Processo de produção e saúde: trabalho e desgaste operário. São Paulo: Hucitec, 1989.

LINHART, D. A Desmedida do capital. São Paulo: Boitempo, 2007.

LOBO, E. M. L.; STOTZ, E. N. Põe o retrato do velho, tira o retrato do velho. O movimento sindical e o fim da Era Vargas: uma avaliação. Revista Maracanã, Rio de Janeiro, v. 2, n. 1, p. 114-152, 2004.

MAAR, W. L. Por uma nova cultura política. Margem esquerda: ensaios marxistas, São Paulo, n. 1, p. 56-65, maio 2003.

MANZANO, S. P. Diagnóstico das condições de trabalho nas montadoras de veículos do ABC e no Paraná: um estudo sobre a modulação da jornada de trabalho e a PLR. 2004. 135 f. Dissertação (Mestrado)Universidade Estadual de Campinas, Campinas, 2004.

MARÇOLA, J. A.; GONÇALVES FILHO, E. V.; FERNANDES, F. C. F. Horas anualizadas e planejamento da capacidade. Revista de Administração, São Paulo, v. 37, n. 4, p. 1629, 2002.

MARTINS, S. S. Participação nos lucros ou resultados: oportunidade ou desafio para o movimento sindical? Revista de Administração Contemporânea, Rio de Janeiro, v. 4, n. 3, p. 47-65, 2000.

MARX, K. O Capital: crítica da economia política. Tradução Regis Barbosa e Flávio R. Kothe. São Paulo: Abril Cultural, 1984a. v. 1.

. O Capital: crítica da economia política. Tradução Regis Barbosa e Flávio R. Kothe. São Paulo: Abril Cultural, 1984b. v. 1, Tomo 2.

MENDONÇA, A. A crise econômica e a sua forma contemporânea. Lisboa: Caminho, 1990.

MEYER, V. Tendências conjunturais da economia brasileira. Conjuntura \& Planejamento, Salvador, n. 26, p. 1-3, jul. 1996.

MOREIRA, V. B. Critérios e condições dos planos de participação nos lucros ou nos resultados e sua inserção no controle de gestão: estudo de casos em indústrias do interior paulista. 2007. 141 f. Dissertação (Mestrado em Controladoria e Contabilidade)-Universidade de São Paulo, Ribeirão Preto, 2007.

NAVARRO, V. Produção e estado de bem-estar: o contexto política das reformas. Lua Nova, São Paulo, n. 28/29, p. 157-199, 1993.

PAIXÃO, A. E. A subjetividade no "novo" tempo de trabalho: um estudo sobre a flexibilidade. 2005. 177 f. Dissertação (Mestrado em Sociologia)-Universidade Federal do Paraná, Curitiba, 2005.

PARKER, M.; SLAUGHTER, J. Unions and management by stress. In: BABSON, S. Lean work: empowerment and exploitation in the global auto industry. Detroit: Wayne State University Press, 1995. p. 41-53.

PENKAL, R. J. Quando a lógica do capital contagia o movimento sindical: qualidade total e o sindicalismo moderado produtivo nos metalúrgicos da Grande Curitiba. 2005. 180 f. Dissertação (Mestrado em Sociologia)-Universidade Federal do Paraná, Curitiba, 2005.

PIGNON, D.; QUERZOLA, J. Ditadura e democracia na produção. In: GORZ, A. Crítica da divisão do trabalho. 
Tradução Estela dos Santos Abreu. 3. ed. São Paulo: Martins Fontes, 2001. p. 91-138.

PREVITALLI, F. S. O caso Mercedes Benz ABC e Campinas. In: ANTUNES, R. Riqueza e miséria do trabalho no Brasil. São Paulo: Boitempo, 2006. p. 147154.

RODRIGUES, I. J. Um laboratório das relações de trabalho: o ABC paulista nos anos 90. Tempo Social, São Paulo, v. 14, n. 1, p. 137-157, 2002.

ROTHSCHILD, E. Capitalismo, tecnologia, produtividade e divisão do trabalho na General Motors. In: MARGLIN, M. et al. Divisão social do trabalho, ciência, técnica e modo de produção capitalista. Porto: Publicações Escorpião, 1974. p. 111131.

SALES, T. B. Trabalho e reestruturação produtiva: o caso da Volkswagen em São Bernardo do Campo - SP. São Paulo: Annablume, 2002.

SELIGMANN-SILVA, E. Desgaste mental no trabalho dominado. Rio de Janeiro: UFRJ; Cortez, 1994.

SINDICATO DOS METALÚRGICOS DO ABC. Redução da jornada, limite de horas extras e reorganização do tempo de trabalho: as propostas dos metalúrgicos do ABC. São Bernardo do Campo: Subseção Dieese, Departamento Jurídico, Departamento de Saúde do Trabalhador, Departamento de Comunicação do Sindicato e Assessoria Jurídica da CNM-CUT, 1993. 38 p. . Acordos coletivos entre o Sindicato dos Metalúrgicos do ABC e a Mercedes Benz do Brasil S/A. São Bernardo do Campo: Sindicato dos Metalúrgicos do ABC/Comissão de Fábrica/Comitê Sindical de Empresa dos Trabalhadores da Mercedes Benz, out. 2001.

SINDICATO DOS METALÚRGICOS DO ABC; FORD MOTOR COMPANY BRASIL LTDA. Acordo coletivo de trabalho sobre férias coletivas e concessão de banco de horas. São Bernardo do Campo, 10 dez. 2008.

SINDICATO DOS METALÚRGICOS DO ABC; VOLKSWAGEM DO BRASIL LTDA. Acordo coletivo: plano de reestruturação fase 2 - Anchieta. São Bernardo do Campo, 10 nov. 2006.

. Aditamento acordo coletivo: plano de reestruturação fase 2. São Bernardo do Campo, 05 jun. 2007.

SOCHACZEWSKI, S. Horas extras: novas formas, velhas intenções. In: CONGRESSO LATINOAMERICANO DE SOCIOLOGIA DO TRABALHO, 5., Montevideo, 2007. Anais... Montevideo: ALAST, 2007. Disponível em: <http:// www.icesi.edu.co/ret/documentos/Ponencias\%20 pdf/287.pdf>. Acesso em: 15 mar. 2010.
STEWART, P. et al. Padrões de controle da mão de obra e a erosão dos padrões de trabalho: rumo a um estudo internacional da qualidade de vida no trabalho e na indústria automobilística (Canadá, Japão e Reino Unido). In: CARDOSO, A.; COVARRUBIAS, A. A indústria automobilística nas Américas: a reconfiguração estratégica e social dos atores produtivos. Belo Horizonte: UFMG, 2006. p. 285-319.

STOTZ, E. N. A reestruturação industrial na visão dos empresários brasileiros. Serviço Social e Sociedade, São Paulo, v. 17, n. 52, p. 86-105, dez. 1996.

. A Participação como fator produtivo; o papel dos CCQ em empresa multinacional. In: ENCONTRO NACIONAL DA ASSOCIAÇÃO BRASILEIRA DE ESTUDOS DO TRABALHO, 5., Rio de Janeiro, 1997. Anais... Rio de Janeiro: Associação Brasileira de Estudos do Trabalho, 1997. Disponível em: <http:// recantodasletras.uol.com.br/arquivos/499591.pdf $>$. Acesso em: 10 mar. 2010.

STOTZ, E. N. et al. Relatório da visita à planta industrial de uma montadora em São Bernardo do Campo-SP e da reunião com comissários de fábrica, diretores e técnicos do Departamento de Saúde do Trabalhador e Meio Ambiente do Sindicato dos Metalúrgicos do ABC, em setembro de 2009. Rio de Janeiro: Fundação Oswaldo Cruz, out., 2009. 11 p. (mimeo).

UVALIĆ, M. Lessons from PEPPER I to PEPPER IV. In: LOWITZSCH, J.; HASHI, I.; WOODWARD, R. The PEPPER IV Report: benchmarking of employee participation in profits and enterprise results in the member and candidate countries of the European Union. Berlin: Institute for Eastern European Studies, Free University of Berlin, 2009. p. 189-189.

VILLEGAS, J. et al. Trabajo y salud en la industria maquiladora mexicana: una tendencia dominante en el neoliberalismo dominado. Caderno de Saúde Pública, Rio de Janeiro, v. 13, Supl. 2, p. 123-134, 1997.

ZYLBERSTAJN, H. A PLR e o mercado de capitais: desenhando a poupança participativa. In: CHAHAD, J. P. Z.; PICHETTI, P. Mercado de trabalho no Brasil: padrões de comportamento e transformações institucionais. São Paulo: FIPE, LTR; Brasília, DF: MTE, 2003a.

. Banco de horas: da justificativa teórica à utilização prática no Brasil. In: CHAHAD, J. P. Z.; PICHETTI, P. Mercado de trabalho no Brasil: padrões de comportamento e transformações institucionais. São Paulo: FIPE, LTR; Brasília, DF: MTE, 2003b. 